4. G. Kumar and K.P. Ray, Broad band microstrip antennas, Artech House, Boston, 2003.

5. S.W. Qu, J.L. Li, J.X. Chen, and Q. Xue, Ultrawideband striploaded circular slot antenna with improved radiation patterns, IEEE Trans. Antennas Propag 55 (2007), 3348-3353.

6. S.H. Choi, J.K. Park, S.K. Kim, and J.Y. Park, A new ultra-wideband antenna for UWB applications, Microwave Opt Technol Lett 40 (2004), 399-401.

7. L. Peng, C.L. Ruan, Y.L. Chen, and X.C. Xun, Analysis of the small slot-loaded elliptical patch antenna with a band-notched for UWB applications, Microwave Opt Technol Lett 51 (2009), 662-664.

8. A.M. Abbosh and M.E. Bialkowski, Design of UWB planar bandnotched antenna using parasitic elements, IEEE Trans Antennas Propag 57 (2009), 796-799.

9. K.S. Ryu, and A.A. Kishk, UWB antenna with single or dual band-notches for lower WLAN band and upper WLAN band, IEEE Trans Antennas Propag 57 (2009), 3942-3950.

10. C.Y.D. Sim, W.T. Chung, and C.H. Lee, A circular-disc monopole antenna with band-rejection function for ultrawideband application, Microwave Opt Technol Lett 51 (2009), 1607-1613.

11. Y.D. Dong, W. Hong, Z.Q. Kuai, and J.Y. Zhou, Band-notched ultra-wideband antenna designed and optimized by current distribution analysis, In: Proceedings of the International Conference on Microwave and Millimeter Wave Technology (ICMMT 2008), 1062-1065.

(C) 2010 Wiley Periodicals, Inc.

\section{A 6.5-50-GHz BATTERY-POWERED COMPACT ROTARY JOINT FOR POLARIZATION ELLIPTICITY MEASUREMENTS}

\section{J.-F. Zürcher}

Ecole Polytechnique Fédérale de Lausanne (EPFL), Laboratoire d'Electromagnétisme et d'Acoustique, Lausanne CH-1015, Switzerland; Corresponding author: JF.Zurcher@epfl.ch

Received 20 May 2010

ABSTRACT: A simple, efficient, and compact rotary joint has been designed, realized, and measured. It has been used intensively to perform polarization ellipticity measurements on various circularly polarized antennas (e.g., helical antennas and circularly polarized horns, used either individually or feeding a lens antennas) operating in millimeter-wave band ( $30 \mathrm{GHz}$ ). (c) 2010 Wiley Periodicals, Inc. Microwave Opt Technol Lett 53:375-379, 2011; View this article online at wileyonlinelibrary.com. DOI 10.1002/mop.25692

Key words: rotary joint; radiation pattern measurements; millimeterwave antennas; polarization ellipticity; spinning (dipole) linear source

\section{INTRODUCTION}

When designing and testing circularly-polarized antennas, a major figure of merit to be measured is the ellipticity of polarization. In this regard, the so-called "spinning dipole" ("spinning linear source," henceforth) technique constitutes a common measurement approach [1]. This technique is characterized by the use of a linearly polarized (LP) range antenna (RA) mounted on a platform that rotates around the axis defined by the line of view between the RA and the antenna under test (AUT). Essentially, the amplitude of the ripple in the RA-AUT transfer function over the angle introduced by this spinning movement amounts to the ellipticity of polarization of the AUT in the direction of the RA-AUT line of view. A typical view of the resulting radiation pattern, plotted together with the envelopes of the transfer function, is depicted in Figure 1.

For the transition between the spinning RA and the (fixed) instrumentation ports, a coaxial rotary joint can be used. A coaxial rotary joint is a section of coaxial line made of two parts: the stationary and the rotating one. Both parts are mechanically aligned and electrically coupled to allow for reliable operation of the joint with optimal insertion loss (IL) and impedance matching while rotating at a speed of a few hundreds of revolutions per minute.

For polarization ellipticity measurements, the rotary joint is driven by an electromotor, which is integrated and properly shielded within the RA platform. This motor determines the maximum revolutions per minute, which together with an appropriate sampling rate of the signal exchanged between the RA and the AUT for each direction of observation provides a fair evaluation of the ellipticity of polarization of the AUT.

The accuracy of the measured polarization ellipticity depends directly on the characteristics of the rotary joint used to spin the LP antenna. Ideally, the IL of the rotary joint should be perfectly constant (and as low as possible) with regard to the rotation angle. In practice, there are always small IL variations

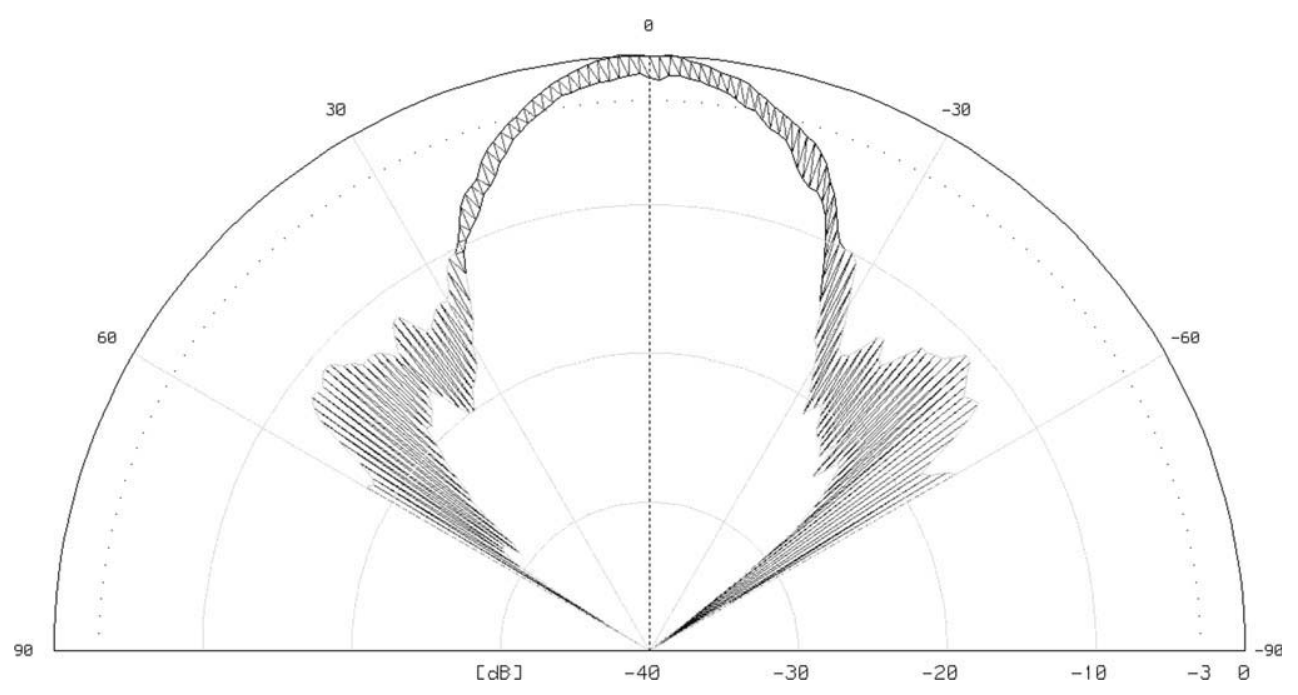

Figure 1 Example of a circularly polarized antenna (helix) measurement using the "spinning linear source" technique 
(called "insertion loss wow" or simply "wow") because of mechanical or electrical imperfections (misalignment, vibrations, bad contacts, etc.). These variations should absolutely be minimized because they constitute a source of systematic errors of the measurement system. In fact, the wow of the rotary joint adds to the polarization ellipticity, resulting in a pessimistic measurement of this parameter. For high quality commercial rotary joints, the typical wow is $\sim 0.1 \mathrm{~dB}$ in the $12-40 \mathrm{GHz}$ band.

Most commercially available coaxial rotary joints use galvanic coupling: both inner and outer conductors of the stationary and rotating part are connected by electrical contacts, often made of elastic strips (beryllium copper) pressing (and rubbing) on the counterpart. This principle has the advantage to be very broadband (from DC to $40 \mathrm{GHz}$ or higher) with reasonable IL (typically $\sim 1 \mathrm{~dB}$ ), but with the inconvenience of being subject to wearing and, thus, to IL degradation with aging. This type of coupling also requires a relatively important mechanical torque to drive the rotary joint, with the need of an external power supply for the electromotor.

For the foreseen application (measurements in the 26-40 $\mathrm{GHz}$ band), the LP antenna to be rotated (in our case, a printed patch antenna) will be very small (typically $10 \times 10$ to $20 \times 20$ $\mathrm{mm}$ ) and lightweight. Therefore, a small and compact rotary joint would be very well suited. An autonomous operation of the electromotor is also found to be desirable and relying, e.g., on standard AA rechargeable batteries. This asks for a very low mechanical torque and, consequently, a low friction rotary joint. The solution proposed is a contactless coupling, i.e., a rotary joint with capacitive coupling.

\section{THE CAPACITIVE COUPLING ROTARY JOINT}

A rotary joint with capacitive coupling has some disadvantages, the most important being a limited bandwidth. It is evident that this type of coupling prevents the use of this kind of rotary joints at low frequencies because of the limitation on the capacitance value. Furthermore, some resonances might occur within the cavity enclosing the joint, degrading the performances at certain frequencies. As our application requires a limited bandwidth (26-40 $\mathrm{GHz}$ ), the capacitive coupling should, however, be adequate.

The main advantages of the proposed rotary joint are a very low mechanical torque (if an adequate bearing is used), and a very high lifetime (practically no wearing). If the radio frequency (RF) design is conveniently optimized, the IL can be kept low and the matching reasonable over the frequency band of interest. A good mechanical design can keep the wow to a minimum, remaining constant with aging.

The design goals in the $26-40 \mathrm{GHz}$ band are following:

- IL: 1-2 dB (not critical, the dynamic range of the measurement facility being $>60 \mathrm{~dB}$ ),

- reasonable matching: $<-10 \mathrm{~dB}$,

- wow as low as possible: $<0.1 \mathrm{~dB}$,

- simple and small design,

- driven by a small, battery powered electromotor (two rechargeable NimH AA batteries), and

- low cost.

To keep realization simple and cost low, the shelf parts were employed wherever possible:

- a pair of SMA connectors for the RF part of the coaxial rotary joint. Though not conceived to operate beyond 18 $\mathrm{GHz}$, a very satisfying performance of this part is achieved after certain modifications of their structure, as it will be shown below,

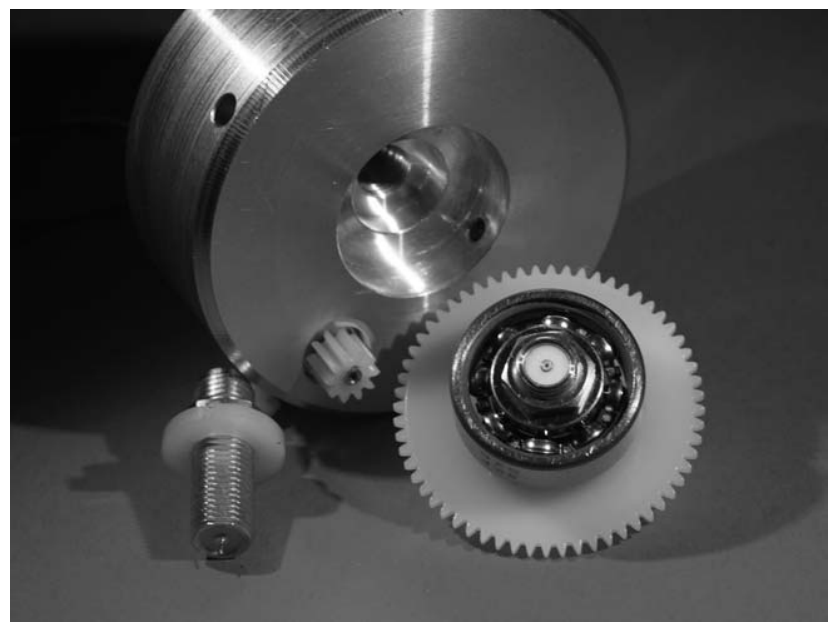

Figure 2 First prototype of the rotary joint (bottom left: fixed SMA section; bottom right: rotating SMA section hold inside the ball bearing; and behind: aluminum cylindrical structure with electromotor and pinion)

- the electromotor is a very cheap coreless miniature type $(7 \mathrm{~mm}$ diameter and $20 \mathrm{~mm}$ long) used in pager applications, and

- plastic gears to couple the electromotor to the coaxial rotary part.

The RF performances were simulated and optimized using Ansoft HFSS [2], starting with very simple models to check the feasibility of the foreseen architecture. The models were then refined to take into account the details of the real RF structure. For the mechanical design, the software tool SolidWorks [3] was used.

\subsection{First Prototype}

Prototyping and measurements of the rotary joint were quite straightforward. It consists of an aluminum cylindrical structure supporting the fixed SMA section and the electromotor. The rotating SMA section is supported by a ball bearing mounted inside the aluminum structure. Figure 2 shows the unassembled rotary joint.

As can be seen in Figure 2, the fixed SMA comprises a small protruding pin (of $200 \mu \mathrm{m}$ diameter) which penetrates through the inner conductor of the rotating SMA. This constitutes the capacitive coupling of the inner conductor. The capacitive coupling for the outer conductor is provided by the small gap between the two outer cylindrical parts of the rotating SMA. In fact, the axial position of the fixed SMA is adjusted so that the gap between it and the rotating outer conductor keeps between 50 and $100 \mu \mathrm{m}$.

The rotary joint performances have been measured with an Agilent E8361A Network Analyzer (10 MHz-67 GHz). The scattering parameters of the joint were found to be satisfactory $\left(\mathrm{S}_{21}\right.$ approximately $-1 \mathrm{~dB}$ from 26 to $40 \mathrm{GHz}$, with a worst value of $-3.1 \mathrm{~dB}$ ).

The IL wow was not measured under real dynamic conditions (at nominal rotating speed), but deduced from the $S_{11}$ measurement variations with the rotating SMA terminated with a matched load. The maximum wow has been estimated with this method to be $\sim 0.3 \mathrm{~dB}$ peak-to-peak.

These results can be considered as very encouraging for a first prototype.

\subsection{Second Prototype}

The first prototype was checked for its weak points, which were found to be:

- mechanical instabilities, mainly because of the ball bearing,

- possible misalignment between fixed and rotating SMA parts, and 


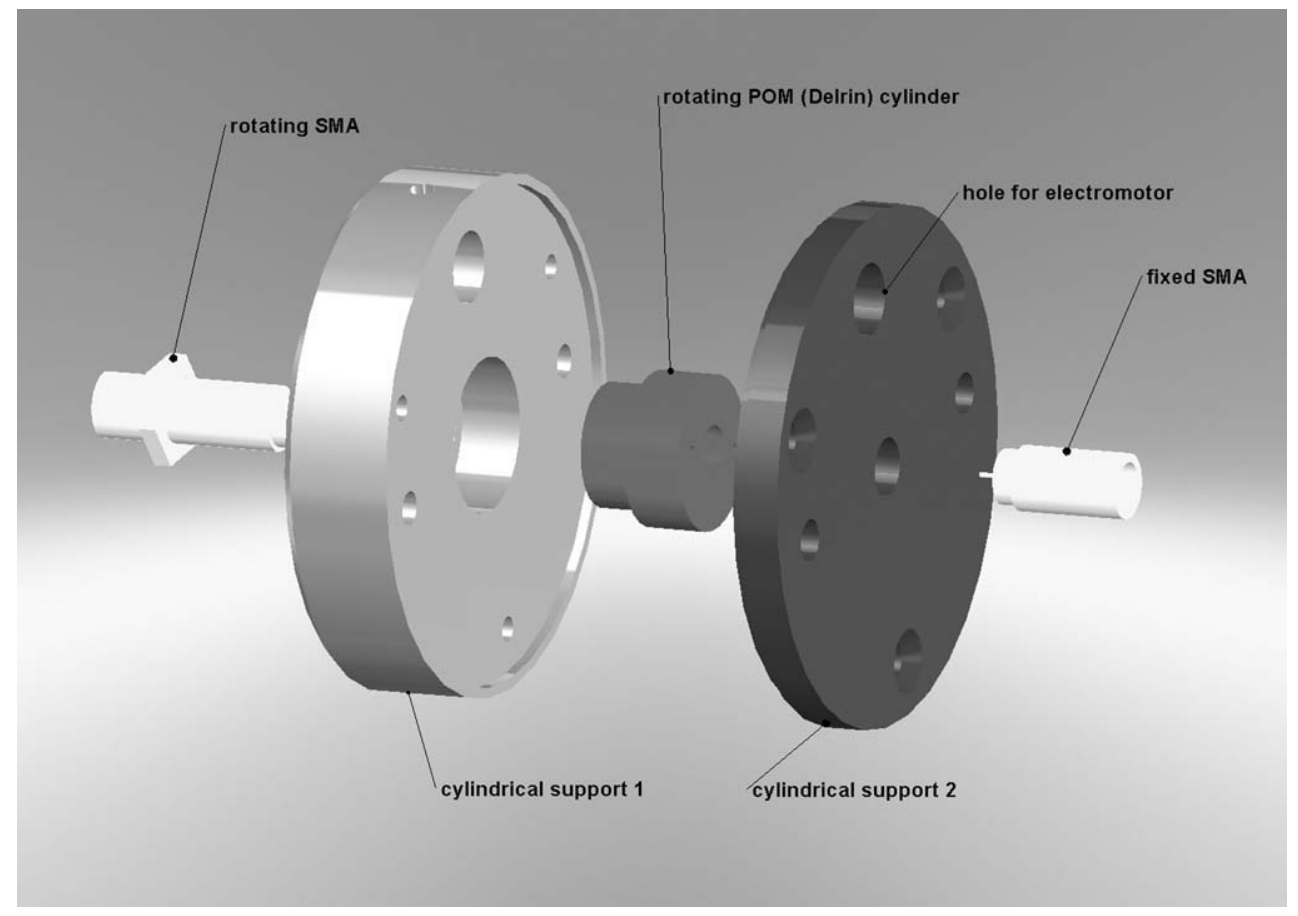

Figure 3 Exploded view of the new mechanical design (without motor and gears)

- RF design susceptible to be further optimized to improve $S_{i j}$ parameters.

Therefore, the mechanical concept was refined to reduce potential instabilities:

- replacement of the ball bearing with a polyoxymethylene (POM, also called Delrin) rotating part,

- substitution of the one piece cylindrical aluminum structure for a two piece stainless steel structure, and

- professional machining with tight tolerances and optimum surface finish.

Figure 3 shows an exploded view of the new mechanical design and Figure 4 shows its realization (disassembled).

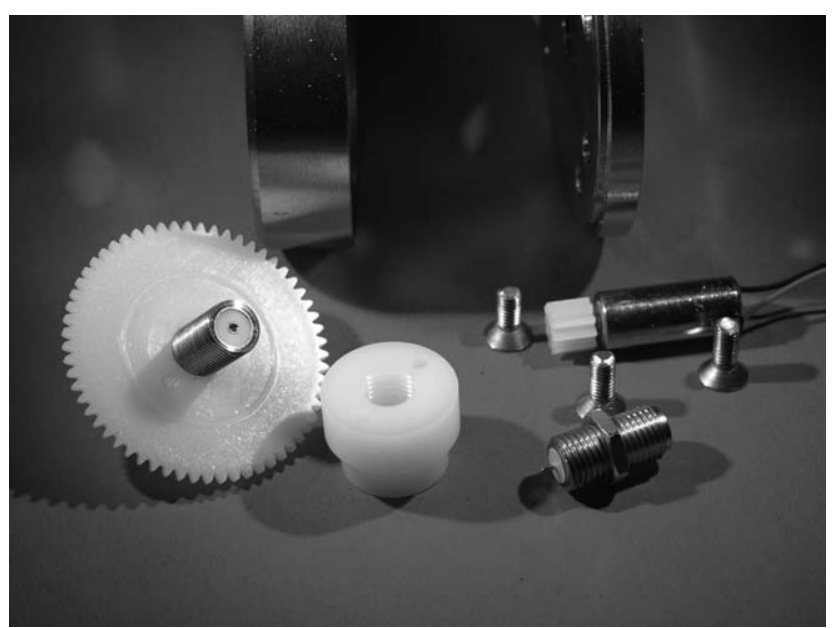

Figure 4 Disassembled rotary joint (bottom left: rotating SMA section with gear and rotating POM cylinder; bottom right: fixed SMA, electromotor with pinion, and screws; behind: stainless steel cylindrical parts)
A $50-\mu$ thick Teflon washer is employed to fill the gap between the two SMA sections, improving the capacitive coupling of the outer conductors. The axial position of the fixed SMA can be adjusted so as to optimize the electrical properties. Then the $S$-parameters were measured between 5 and $50 \mathrm{GHz}$ with an Agilent E8361A Network Analyzer. In Figures 5 and 6, measured $S$-parameters are compared with simulation results. It must be pointed out that simulations only account for the rotary joint itself, whereas for the measurements with the Network Analyzer a $1.85 / 2.92-\mathrm{mm}$ coaxial transition has been attached to each side of the rotary joint. This may well justify the differences between both results, which keep, however, in quite reasonable agreement. To properly account for reflections at the interfaces of such transitions by simulation, a precise description of the geometry of these transitions would be required.

The $S_{21}(\sim \mathrm{IL})$ remains below $3 \mathrm{~dB}$ from 6.5 to $50 \mathrm{GHz}$, and under $2 \mathrm{~dB}$ from $\sim 10$ to $45 \mathrm{GHz}$. Its best value is $\sim 0.7 \mathrm{~dB}$.

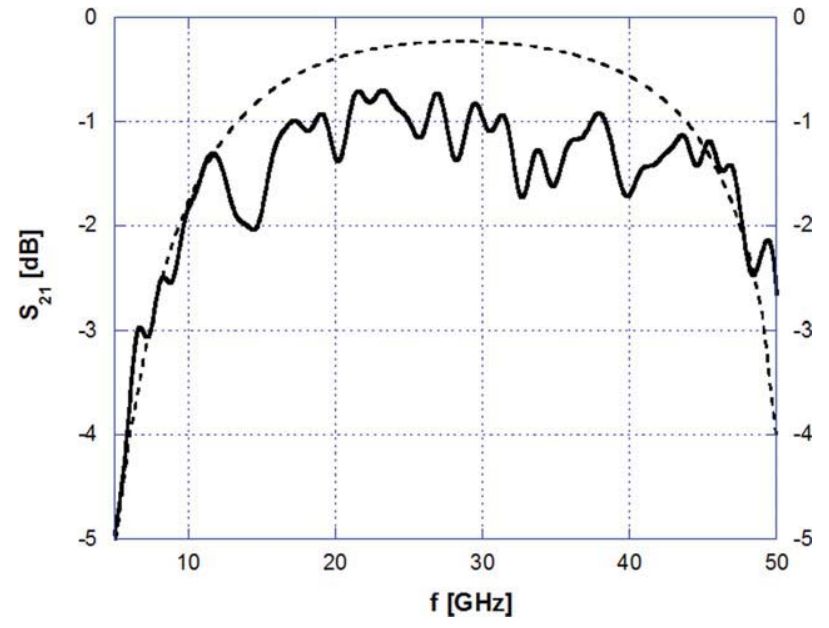

Figure 5 Measured $\mathrm{S}_{21}$ from 5 to $50 \mathrm{GHz}$. [Color figure can be viewed in the online issue, which is available at wileyonlinelibrary.com] 


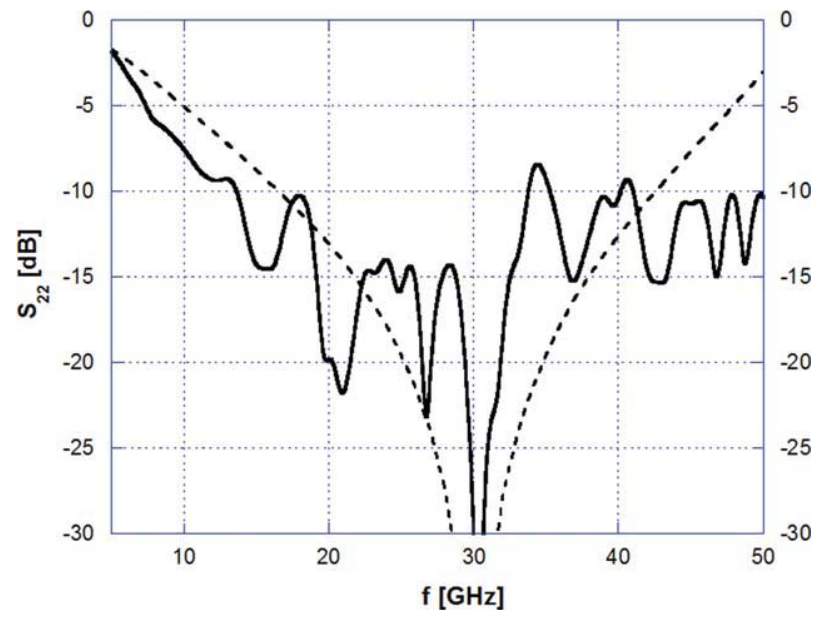

Figure 6 Measured $\mathrm{S}_{22}$ from 5 to $50 \mathrm{GHz}$. [Color figure can be viewed in the online issue, which is available at wileyonlinelibrary.com]

Below $10 \mathrm{GHz}$, the increased IL due to the capacitive coupling is clearly visible.

The $S_{22}$ (matching seen from the fixed SMA) is below -10 $\mathrm{dB}$ from 13.8 to $50 \mathrm{GHz}$, except at two points $\sim 34.5 \mathrm{GHz}(-8$ $\mathrm{dB})$ and $40.4 \mathrm{GHz}(-9 \mathrm{~dB})$.

These measurements include the two transitions needed to connect the $1.85-\mathrm{mm}$ cable connectors from the Network Analyzer to the SMA of the rotary joint. So the intrinsic performance of the rotary joint itself is probably better.

The $S_{21}$ wow has been deduced from measured $S_{11}$ variations (rotating SMA terminated with a matched load) during rotation at nominal speed. The measurements have been automatized (Network Analyzer driven by computer program, 1000 measurements per frequency). The measured wow was $0.065 \mathrm{~dB}$ at $10 \mathrm{GHz}$, $0.016 \mathrm{~dB}$ at $20 \mathrm{GHz}, 0.023 \mathrm{~dB}$ at $30 \mathrm{GHz}$, and $0.057 \mathrm{~dB}$ at 40 $\mathrm{GHz}$. So, we can state with confidence that the wow is $<0.1 \mathrm{~dB}$

The rotary joint has been tested during an intensive measurement campaign on lens/horn combination antenna assemblies $\sim 30 \mathrm{GHz}$. The linear source used was a rectangular patch antenna etched on RT/Duroid 5870 substrate (see Fig. 7).

The rotary joint performed very well. Its current consumption was $\sim 40-50 \mathrm{~mA}$ at the nominal voltage of $2.4 \mathrm{~V}$, with battery autonomy of $\sim 30 \mathrm{~h}$.

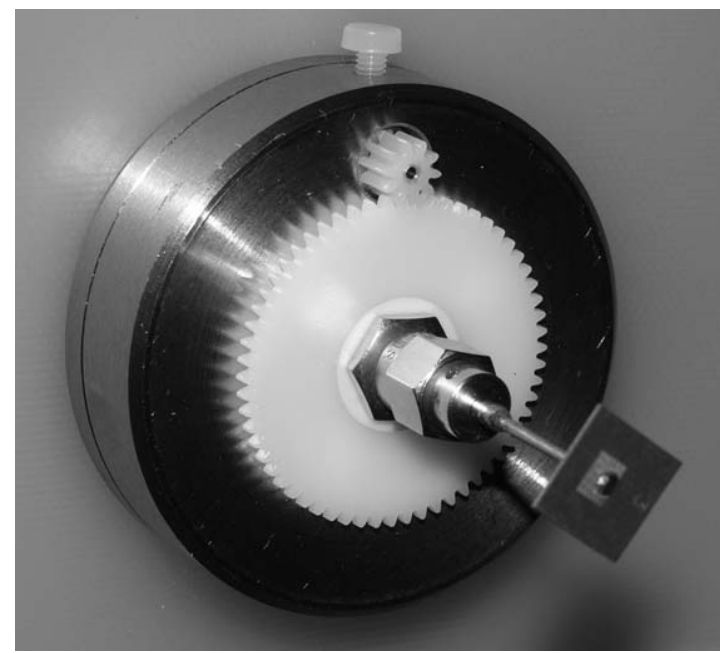

Figure 7 The rotary joint with a 29.3-GHz LP patch antenna attached

Figure 8 shows an example of the polarization ellipticity measurement carried out at $29.3 \mathrm{GHz}$ with this rotary joint: the AUT consists of a LP circular-waveguide horn feeding a $60-\mathrm{mm}$ diameter Teflon lens, followed by a meander-line polarizer [4] used to convert the LP into circularly polarized.

\section{CONCLUSIONS}

The rotary joint described here fulfills our initial measurement goals: within the required $26-40 \mathrm{GHz}$ band, its IL is comprised between 0.7 and $1.6 \mathrm{~dB}$, and the wow is well below $0.1 \mathrm{~dB}$. The $S_{22}$ is below $-10 \mathrm{~dB}$ over the entire frequency band, except $\sim 34.5 \mathrm{GHz}$, where it punctually reaches $-8 \mathrm{~dB}$.

This rotary joint allowed us to conduct a campaign of polarization ellipticity measurements in our laboratory's facilities within the $30 \mathrm{GHz}$ band with excellent results. Between 10 and $48 \mathrm{GHz}$, the IL of the rotary joint remains under $2 \mathrm{~dB}$. If the matching is not too critical for the application, the total usable bandwidth ranges from 6.5 to $50 \mathrm{GHz}$ with an IL $<3 \mathrm{~dB}$. A reduced wow of $<0.1 \mathrm{~dB}$ allows for an excellent accuracy in the measurement of the polarization ellipticity. No performance degradation could be observed after $>50 \mathrm{~h}$ of operation, with battery autonomy of $\sim 30 \mathrm{~h}$.

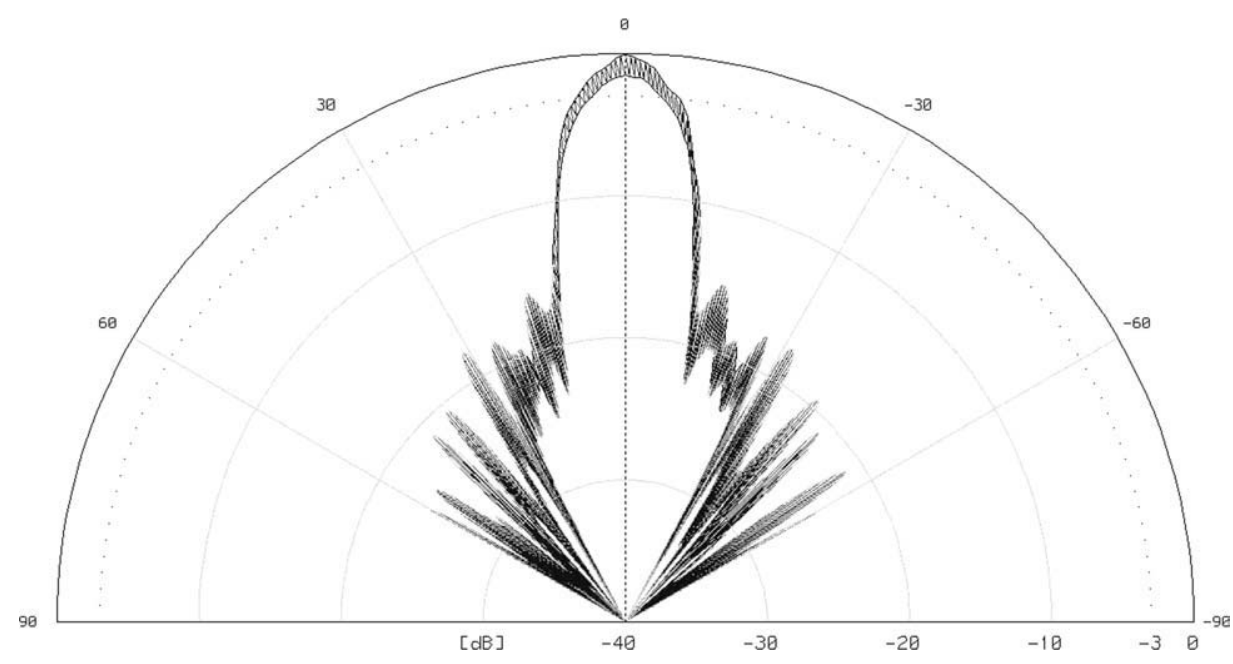

Figure 8 Antenna (LP horn/Teflon lens/polarizer) measured at $29.3 \mathrm{GHz}$ using the rotary joint 


\section{ACKNOWLEDGMENTS}

The author thanks J.-P. Brugger and K. Collomb from the mechanical workshop of STI/Ecole Polytechnique Fédérale de Lausanne for their precious advice and the accurate manufacturing of the second prototype of the rotary joint.

\section{REFERENCES}

1. G.E. Evans, Antenna measurement techniques, Artech House, Norwood, MA (ISBN 0-89006-375-3 pp 77-80).

2. Ansoft HFSS v. 12, available at: www.ansoft.com/products/hf/hfss/

3. SolidWorks 2009 SP5.0, available at: www.solidworks.com/

4. L. Young, L.A. Robinson, and C.A. Hacking, Meander-line polarizer, IEEE Trans Antennas Propag,21 (1973), 376-378.

(C) 2010 Wiley Periodicals, Inc.

\section{K-BAND POWER DIVIDER WITH METAL BRIDGE STRUCTURES FOR SIZE REDUCTION USING CMOS TECHNOLOGY}

\author{
Han-Yeol Yu, Sung-Sun Choi, and Yong-Hoon Kim \\ Department of Mechatronics, Gwangju Institute of Science and \\ Technology, 1 Oryong-dong, Puk-gu, Gwangju 500-712, Korea; \\ Corresponding author: yhkim@gist.ac.kr
}

Received 20 May 2010

ABSTRACT: A K-band power divider with metal bridge structures, which is based on the Wilkinson type is proposed using a standard 0.18 $\mu \mathrm{m} C M O S$ process. The metal bridge structures are applied to the power divider to achieve small size. Additionally, slow-wave structures such as meandered line and slot pattern ground are used for small chip size and high performance. The proposed power divider shows an improved slow-wave factor of $8.2 \%$ compared with a power divider with the conventional meandered line structure. The proposed power divider presents a size of $306 \times 296 \mu \mathrm{m}$ and wide bandwidth of $58 \%$ for isolation $<15 d B$. (C) 2010 Wiley Periodicals, Inc. Microwave Opt Technol Lett 53:379-381, 2011; View this article online at wileyonlinelibrary.com. DOI 10.1002/mop.25691

Key words: CMOS; power dividers; slow-wave factor; Wilkinson power dividers

\section{INTRODUCTION}

Millimeter-wave integrated circuits (IC) chips have been using for many applications such as automotive radars, wireless local area networks, and wireless personal area networks. Recently, the IC chips are advancing toward a system on-chip consisting of not only RF transceiver but also a digital signal processor. For an on-chip solution, small size is considered as an important factor. In the IC chips, passive circuits such as filters, baluns, and power dividers occupy the most area. Especially, the power dividers take large size for multichannel architectures, which are used for high resolution radars [1]. Until now, many researches for power dividers with small size have been published in Refs $2-4$. These articles presented electromagnetic band gap [2] or synthetic quasi-TEM transmission line structures $[3,4]$ to achieve small chip size. Although, these structures can achieve small chip size, the size reduction has limitation by design rules such as minimum line space and width.

In this letter, we propose a K-band Wilkinson type power divider with slow-wave structures in a $0.18-\mu \mathrm{m}$ CMOS technology. The slow-wave structures consist of meandered line, slot pattern ground, and metal bridges. The size of the proposed power divider is reduced by not only the meandered line and slot pattern ground but also the proposed metal bridge structures.

\section{CONFIGURATION AND DESIGN}

The designed power divider is symmetrical with respect to the longitudinal direction as shown in Figure 1; Figure 2 shows the detailed geometry of specific area in the power divider. According to design procedures for the Wilkinson power divider [5], a quarter wavelength transmission line of $70.7 \Omega$ between the input and output ports and an isolation resistor of $100 \Omega$ between the output ports are selected for impedance matching, good isolation, and equal power division. However, because the quarter wavelength in the $\mathrm{SiO} 2$ layer which has a dielectric constant of 3.9 is several millimeters long, the meandered line structure is used to reduce the size of the power divider. Also, the slot pattern ground with periodic rectangular patterns is applied under the line. The slow-wave effect by the slot pattern ground can reduce the size of the power divider. However, this structure has limitation for reducing the size of the power divider by design rules such as minimum line space and width. To mitigate this problem, the metal bridges are applied between the line and the slot pattern ground. The metal bridges increase the capacitance of the line. This capacitance with the inductance of the line causes slow-wave effect by a periodic structure. As a result, these metal bridges reduce the more the size of the power divider.

The power divider was fabricated on a silicon substrate with a dielectric constant of 11.9 and $300 \mu$ m thickness in the 0.18 $\mu \mathrm{m}$ CMOS process. The meandered line is made by Metal 6 with $2.3 \mu \mathrm{m}$ thickness and $6 \mu \mathrm{m}$ width to lower insertion loss and match for $50 \Omega$. The slot pattern ground is made by Metal 1 with $0.56 \mu \mathrm{m}$ thickness, and each pattern has a size of $11 \times 20$ $\mu \mathrm{m}$ as shown in Figure 2. The distances between the patterns are chosen to be A, $36 \mu \mathrm{m}$, and B, $30 \mu \mathrm{m}$, respectively. The metal bridges under the meandered line are composed of Metal 5 with $0.56 \mu \mathrm{m}$ thickness and $5 \mu \mathrm{m}$ width. Metal via holes are used to

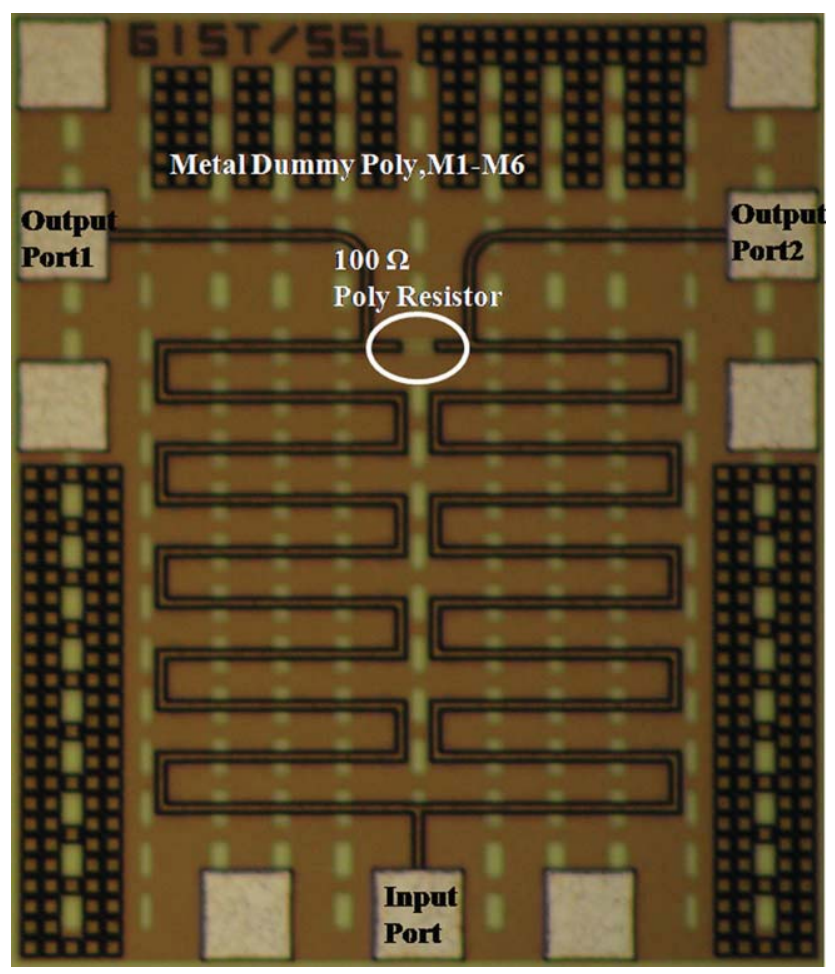

Figure 1 Chip micrograph of designed power divider. [Color figure can be viewed in the online issue, which is available at wileyonlinelibrary.com] 